University of Nebraska - Lincoln

DigitalCommons@University of Nebraska - Lincoln

Faculty Publications, Department of Psychology

Psychology, Department of

$12-2019$

\title{
Renaming Me: Assessing the Influence of Gender Identity on Name Selection
}

\author{
Sharon Obasi \\ University of Nebraska at Kearney, obasis2@unk.edu \\ Richard Mocarski \\ University of Nebraska-Kearney, mocarskira@unk.edu \\ Natalie Holt \\ University of Nebraska-Lincoln \\ Debra Hope \\ University of Nebraska - Lincoln, dhope1@unl.edu \\ Nathan Woodruff \\ University of Nebraska-Lincoln
}

Follow this and additional works at: https://digitalcommons.unl.edu/psychfacpub

Part of the Child Psychology Commons, Developmental Psychology Commons, Development Studies Commons, Gender and Sexuality Commons, and the Personality and Social Contexts Commons

Obasi, Sharon; Mocarski, Richard; Holt, Natalie; Hope, Debra; and Woodruff, Nathan, "Renaming Me: Assessing the Influence of Gender Identity on Name Selection" (2019). Faculty Publications, Department of Psychology. 1025.

https://digitalcommons.unl.edu/psychfacpub/1025

This Article is brought to you for free and open access by the Psychology, Department of at DigitalCommons@University of Nebraska - Lincoln. It has been accepted for inclusion in Faculty Publications, Department of Psychology by an authorized administrator of DigitalCommons@University of Nebraska - Lincoln. 


\title{
Renaming Me: Assessing the Influence of Gender Identity on Name Selection
}

\author{
Sharon N. Obasi, ${ }^{1}$ Richard Mocarski, ${ }^{2}$ Natalie Holt, ${ }^{3}$ \\ Debra A. Hope, ${ }^{3}$ \& Nathan Woodruff 4 \\ 1 Department of Family Studies, University of Nebraska at Kearney \\ 2 Office of Sponsored Programs and Research Development, University of \\ Nebraska at Kearney \\ 3 Department of Psychology, University of Nebraska-Lincoln \\ 4 Trans Collaborations, Department of Psychology, University of \\ Nebraska-Lincoln \\ Corresponding author: Sharon N. Obasi, University of Nebraska at Kearney, \\ 2504 9th Ave., Kearney, Nebraska, 68849 USA. E-mail: obasis2@unk.edu
}

\begin{abstract}
Our identity is our name connected with a specific face and body. Yet, our name, a critical aspect of the "names-body-identity" nexus is rarely selfselected. The naming of a newborn is often the purview of family and the name selected is often linked to the sex assigned to the child. Assigned sex, however, may differ from gender identity. Renaming, the process of selecting and using a new name, can be instrumental in expressing an authentic gender identity. Thus, gender identity and renaming were examined among transgender and gender nonconforming (TGNC) adults using an online survey. Participants indicated that the recognition of their gender identity often involved the renaming of self or the use of a new name reflective of that gender identity. Several factors influenced name selection including input from familial sources. This exploratory study offers insight into the connection between gender and naming strategies in an adult TGNC population.
\end{abstract}

Keywords: gender identity, renaming, namesaking, TGNC, family

Published in NAMES, Vol. 67 No. 4, December 2019, 199-211.

DOI 10.1080/00277738.2018.1536188

Copyright (c) 2018 American Name Society. Used by permission. 


\section{Introduction}

Our name is integral to our identity. Forenames and surnames may reveal diverse aspects about us including our racial and ethnic heritage, gender, age, socioeconomic class, place of birth, and/or place of residence (Pilcher, 2016). Yet, the one attribute that is imbued with the most information about us is not always self-selected. Selecting a name for a newborn is often the purview of parents, family members, and other nonfamilial sources including friends, strangers, books, websites, blogs, and other means of information. Several strategies may be employed in the process of name selection. One strategy, namesaking, or naming a child after a specific family member, may be considered a unique form of parental investment advertising the connection between newborns and specific family members or kinfolk (Obasi, 2016). But, what processes take place when we are able to self-select our names or rename ourselves? This paper explores this question by examining the process of renaming and the name selection strategies used by persons who identify as transgender or gender nonconforming (TGNC).

Traditional conceptualizations of gender as binary are increasingly proving to be limited with the growing recognition of a spectrum of gender identity (Rahilly, 2015). Definitions of gender identity and expression that may fall within this spectrum continue to evolve over time (Reisner et al., 2015). Briefly, however, TGNC persons are those whose gender identity differs from assigned sex at birth. Transgender persons may include individuals who are trans-masculine (e.g. transman or female-to-male (FTM)) or trans-feminine (e.g. trans-woman or male-to-female (MTF)). Gender nonconforming persons are individuals whose gender identity may not fit exclusively into a binary category (e.g. male or female), may embody either category (male and female) or neither category (neither male nor female, e.g. genderqueer). Cisgender persons are individuals whose gender identity poses no conflict with their assigned sex at birth.

Unquestionably, there is a link between presumed gender identity and expression connected to biological sex and naming. Anecdotal and empirical evidence suggests that as soon as parents and others (e.g. family, friends) are made aware of the sex of a baby, lists of genderspecific names are formulated (Slepian \& Galinsky, 2016). Indeed, even if the sex of the baby is not revealed there are strategies (e.g. 
namesaking) employed to select names. Once a newborn has been given a forename based on its sex assigned at birth a plethora of cultural practices ensue to construct or reinforce gender identity such as color-specific clothing, nurseries, birth announcements, toys, and so on (Pilcher, 2016). According to Pilcher (2016) there is a "namesbody-identity" nexus such that our identity is resultant of our name applied to a specific face and body. Hence, the importance of identity documents (e.g. passports, drivers' licenses) that verify identity through the matching of names and physical appearance.

The connection between gender and naming could be directly investigated by focusing on TGNC persons. For these individuals, the selection and use of a personal name is more reflective of their gender as it can be part of the process of recognizing their gender identity and ex-

pressing that identity. This renaming process can be instrumental to complete a transition from a gender identity and its socially expected expression based on sex assigned at birth, to a TGNC person's authentic gender identity and expression. Renaming, choosing to use a different name, can serve as a public expression of this change. In popular culture, the renaming process has been demonstrated by Chaz Bono, Laverne Cox, Caitlin Jenner, Chelsea Manning, Janet Mock, and others (Haberman, 2015). There is limited research on the process by which TGNC persons go about selecting names to reflect their gender identity. Thus, the purpose of this exploratory study is to examine the factors that could influence choice of names and the process of selecting a name reflective of gender identity by TGNC persons.

\section{Methodology}

\section{Participants}

The process by which names are selected to reflect identity was examined among 55 TGNC persons who were 19 years of age and older and who took part in a larger online study. Of the 55 participants, 31\% (17/55) self-identified as trans-feminine (e.g. Transwoman/Transwoman/Male to Female (MTF)/ Woman); 36.3\% (20/55) self-identified as trans-masculine (e.g Transman/Transman/Female to Male (FTM)/Man); while 32.7\% (18/55) self-identified as gender nonconforming (e.g. nonbinary/Genderqueer/Bigender/Another gender 
minority). At birth, 36.3\% (20/55) of participants were assigned male; 63.6\% (35/55) were assigned female.

Data collection for the larger online study was completed in October and November 2017. Recruitment emails were sent to LGBT organizations across the United States and posted in social media and list-serves. The postings included a link to the Qualtrics-hosted survey and invited TGNC-identified participants over the age of 19 (age of consent in Nebraska) to complete the online surveys. The larger study included the validation of a new measure for use in psychological services so a variety of mental health and gender-specific self-report measures were included. Participants received a \$10 online gift card within 24 hours of taking part in the study.

\section{Measures}

Participants completed a survey whereby they shared demographic information and were also given the opportunity to discuss in their own words the factors that informed their renaming process. Demographic questions focused on age, race/ethnicity, relationship status, employment, population density of place of residence, annual household income, birth family type, birth order, educational level, and religious affiliation. Name selection questions focused on the similarity between birth names and current names, the age at which respondents started to use their current names and the process by which respondents selected their names to be in concert with their gender identity. Analyses of variance were used for continuous variables and chisquare analyses for categorical variables.

\section{Results}

Table 1 illustrates comparisons of demographic characteristics of the three groups of respondents: trans-masculine, trans-feminine, and gender nonconforming.

The average age of participants was 32.9 years with a range of 19 to 73. There were no significant differences in age but the trans-feminine group was on average older than the trans-masculine and the gender nonconforming groups. The average age of the trans-feminine group 
Table 1. Demographic Information by Percentage.

Trans-feminine $=$ Transwoman/Trans Woman/MTF/Woman; N=17

Trans-masculine $=$ Transman $/$ Trans Man $/$ FTM/Man; $\mathrm{N}=20$

Gender nonconforming $=$ Nonbinary/Genderqueer/Agender/Bigender/Another Gender Minority; N=18

\begin{tabular}{|c|c|c|c|c|}
\hline & $\begin{array}{l}\text { Trans- } \\
\text { feminine } \\
\mathrm{N}=17\end{array}$ & $\begin{array}{l}\text { Trans- } \\
\text { masculine } \\
\mathrm{N}=20\end{array}$ & $\begin{array}{c}\text { Gender } \\
\text { nonconforming } \\
\mathrm{N}=18\end{array}$ & Statistic \\
\hline Age & & & & $F(2,54)=1.5$, n.s. \\
\hline $19-24$ years old & 23.5 & 20 & 27.8 & \\
\hline 25-34 years old & 47.1 & 50 & 61.1 & \\
\hline 35-44 years old & 0 & 5 & 5.6 & \\
\hline $45-54$ years old & 0 & 25 & 0 & \\
\hline$>55$ years old & 29.4 & 0 & 5.6 & \\
\hline Race/Ethnicity & & & & $\chi^{2}(12, N=55)=8.09$, n.s. \\
\hline EuroAmerican/Caucasian/White & 76.5 & 60 & 55.6 & \\
\hline AfricanAmerican/Black & 5.9 & 10 & 5.6 & \\
\hline Native American/American Indian/Alaskan Native & 0 & 5 & 5.6 & \\
\hline Asian American/Pacific Islanders & 5.9 & 0 & 5.6 & \\
\hline Hispanic & 5.9 & 15 & 10.9 & \\
\hline Other ( 2 or moreraces or ethnicities) & 5.9 & 10 & 16.7 & \\
\hline Sexual Orientation & & & & $\chi^{2}(14, N=55)=28.85, p<.05$ \\
\hline Straight/Heterosexual & 35.3 & 30 & 0 & \\
\hline Gay & 11.8 & 20 & 5.6 & \\
\hline Lesbian & 17.6 & 5 & 11.1 & \\
\hline Queer & 0 & 15 & 33.3 & \\
\hline Bisexual & 23.5 & 15 & 0 & \\
\hline Pansexual & 5.9 & 0 & 16.7 & \\
\hline Asexual & 5.9 & 0 & 16.7 & \\
\hline Create own term & 0 & 15 & 16.7 & \\
\hline Relationship Status & & & & $\chi^{2}(10, N=55)=10.9$, n.s. \\
\hline Married & 29.4 & 30 & 16.7 & \\
\hline Single, never married & 29.4 & 30 & 33.3 & \\
\hline Divorced/separated & 17.6 & 5 & 0 & \\
\hline In a long-term relationship & 5.9 & 25 & 16.7 & \\
\hline Partnered without legal recognition & 5.9 & 0 & 16.7 & \\
\hline Dating & 11.8 & 10 & 16.7 & \\
\hline Employment & & & & $\chi^{2}(10, N=55)=9.83$, n.s. \\
\hline Full-time employment & 47.1 & 65 & 44.4 & \\
\hline Part-time employment & 23.5 & 10 & 16.7 & \\
\hline Unemployed & 11.8 & 0 & 22.2 & \\
\hline Student & 5.9 & 15 & 11.1 & \\
\hline Disabled/Unable to Work & 5.9 & 10 & 0 & \\
\hline Retired & 5.9 & 0 & 5.6 & \\
\hline Population Density of Place of Residence & & & & $\chi^{2}(6, N=55)=3.79$, n.s. \\
\hline Urban >50,000 people & 47.1 & 50 & 66.7 & \\
\hline Urban Cluster 2,500-50,000 & 41.2 & 30 & 22.2 & \\
\hline Rural & 5.9 & 10 & 11.1 & \\
\hline Preferred not to answer & 5.9 & 10 & 0 & \\
\hline Annual Household Income & & & & $\chi^{2}(12, N=55)=4.76$, n.s. \\
\hline$<\$ 10,000$ & 5.9 & 5 & 11.1 & \\
\hline$\$ 10,000-\$ 29,999$ & 29.4 & 25 & 22.2 & \\
\hline$\$ 30,000-\$ 49,999$ & 23.5 & 25 & 22.2 & \\
\hline$\$ 50,000-\$ 69,999$ & 11.8 & 15 & 22.2 & \\
\hline$\$ 70,000-\$ 89,000$ & 5.9 & 10 & 5.6 & \\
\hline$\$ 90,000-\$ 149,000$ & 23.5 & 10 & 11.1 & \\
\hline$>\$ 150,000$ & 0 & 10 & 5.6 & \\
\hline
\end{tabular}


Table 1. Demographic Information by Percentage (continued).

Trans-feminine $=$ Transwoman/Trans Woman/MTF/Woman; $\mathrm{N}=17$

Trans-masculine $=$ Transman/Trans Man/ FTM/Man; N=20

Gender nonconforming = Nonbinary/Genderqueer/Agender/Bigender/Another Gender Minority; N=18

\begin{tabular}{|c|c|c|c|c|}
\hline & $\begin{array}{c}\text { Trans- } \\
\text { feminine } \\
\mathrm{N}=17\end{array}$ & $\begin{array}{l}\text { Trans- } \\
\text { masculine } \\
\mathrm{N}=20\end{array}$ & $\begin{array}{c}\text { Gender } \\
\text { nonconforming } \\
\mathrm{N}=18\end{array}$ & Statistic \\
\hline Education & & & & $\chi^{2}(14, N=55)=11.61$, n.s. \\
\hline Less than high school & 5.9 & 0 & 5.6 & \\
\hline High school diploma/GED & 11.8 & 5 & 0 & \\
\hline Some College & 17.6 & 0 & 27.8 & \\
\hline Associate's degree & 5.9 & 15 & 0 & \\
\hline Bachelor's degree & 23.5 & 25 & 27.8 & \\
\hline Some graduate school & 5.9 & 5 & 5.6 & \\
\hline $\begin{array}{l}\text { Master's degree, professional degree, } \\
\text { or doctoral degree (e.g., M.A., M.D., Ph.D.) }\end{array}$ & 11.8 & 5 & 22.2 & \\
\hline Trade school degree or certificate & 17.6 & 511.1 & & \\
\hline Family Type & & & & $\chi^{2}(14, N=54)=2.2$, n.s. \\
\hline Two-parent home & 76.5 & 60 & 64.7 & \\
\hline Single-parent home & 23.5 & 30 & 29.4 & \\
\hline Kinship home & 0 & 10 & 5.9 & \\
\hline Birth Order & & & & $\chi^{2}(2, N=55)=1.18$, n.s. \\
\hline First born & 47.1 & 50 & 33.3 & \\
\hline Later born & 52.9 & 50 & 66.7 & \\
\hline Affiliated with Religion & & & & $\chi^{2}(2, N=55)=2.34$, n.s. \\
\hline Yes & 64.7 & 50 & 38.9 & \\
\hline No & 35.3 & 50 & 61.1 & \\
\hline Attend a Place of Worship & & & & $\chi^{2}(2, N=55)=.95$, n.s. \\
\hline Yes & 35.3 & 35 & 22.2 & \\
\hline No & 64.7 & 65 & 77.8 & \\
\hline
\end{tabular}

was 37.5 years while the average age of the trans-masculine group was 31.8 years and 29.8 years for the gender nonconforming participants.

The majority of respondents in this study identified as White (63.6\%). African American/Black respondents constituted 7.3\% of respondents, Native Americans/American Indians/Alaskan Natives constituted 3.6\% of respondents, Asian Americans constituted 3.6\% of respondents, Hispanics constituted $10.9 \%$ of respondents, and multiracial participants (persons with two or more racial/ ethnic identities) constituted $10.9 \%$ of respondents. There were no significant differences in race/ethnicity based on gender identity.

Statistical analysis revealed a significant difference between groups with respect to sexual orientation (heterosexual vs. non-heterosexual (queer)), $\chi^{2}(14, N=55)=40.1, p<.05$. Significantly more transmasculine (35.5\%) and transfeminine respondents (30\%) identified as heterosexual while significantly more gender nonconforming persons $(33.3 \%)$ identified as queer. 
There were no other significant differences between gender identity groups based on the other demographic variables assessed such as level of education, relationship status, employment, place of residence, income level, and religious affiliation.

Table 2 illustrates comparison between groups on birth names, namesaking (being named after a specific family member), and name selection strategies.

Statistical analysis revealed a significant difference between groups regarding their birth names, $\chi^{2}(14, N=55)=40.1, p<$ respondents (76.5\%) had typically masculine birth names whereas most transmasculine $(65 \%)$ and gender nonconforming respondents $(77.8 \%)$ had typically feminine birth names. There were no significant differences between groups with respect to namesaking, that is, being named after a specific family member. Of those who were namesaked, however, there was a statistically significant difference between groups, $\chi^{2}(2, N$ 9) $9, \mathrm{p}<$.05. Namesaked respondents were more likely to be named after paternal relatives than maternal relatives.

Regarding renaming, the majority of respondents currently used a forename that differed from their birth name, $\chi^{2}(2, N 55) 5.98, p$ $<.05$. The data revealed that $88.2 \%$ of trans-feminine respondents, $90 \%$ of trans-masculine respondents, and $61.1 \%$ of gender nonconforming respondents used forenames that differed from their birth names. Current forenames used were reflective of gender identity, $\chi^{2}(4, N 43) 23.21, p<$.01. The majority of trans-feminine (80\%) currently use traditionally feminine names, the majority of transmasculine $(61 \%)$ currently use traditionally masculine names while amongst the gender nonconforming persons 50\% use gender neutral names, 20\% use traditionally masculine names, and 30\% traditionally feminine names. There was also a statistically significant difference in the age at which participants started using their chosen name, $\mathrm{F}(2,38)=$ 3.15, $\mathrm{p}=$ Trans-masculine participants on average started using their chosen name at 19.4 years of age while trans-feminine participants on average started using their chosen name much later, at 32 years of age. Gender nonconforming participants started using their chosen name on average at 27.6 years of age.

In the online survey, participants were given the opportunity to share in their own words the process by which they chose their new forename (first name). A preliminary analysis of information shared 
Table 2. Gender Identity, Namesaking, and Name Selection by Percentage

Trans-feminine $=$ Transwoman/Trans Woman/MTF/Woman; $\mathrm{N}=17$

Trans- masculine $=$ Transman $/$ Trans Man/ FTM/Man; N=20

Gender nonconforming $=$ Nonbinary/Genderqueer/Agender/Bigender/Another Gender Minority; N=18

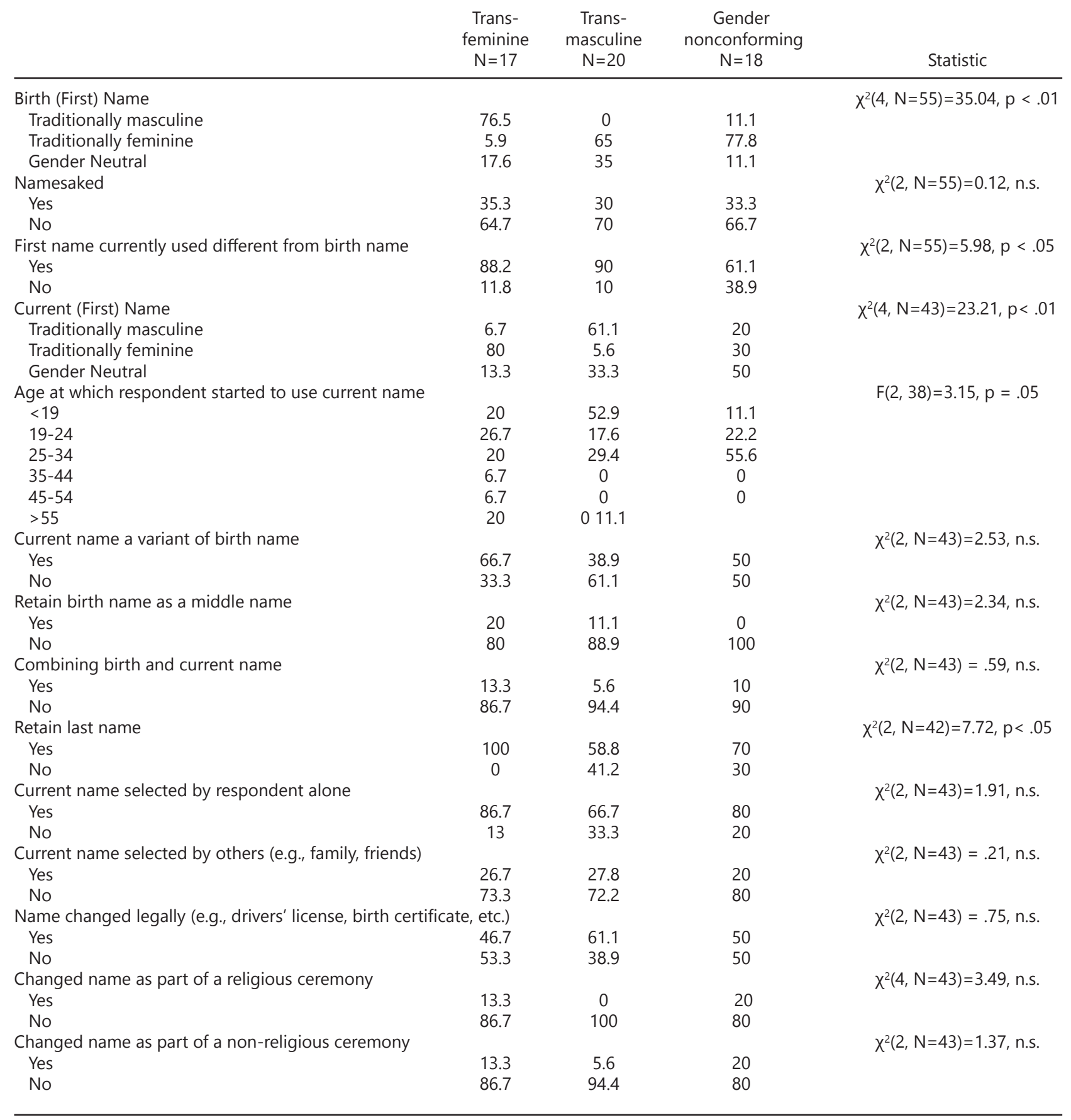


identified three emergent themes: (1) chosen name selected in order to honor family or heritage; (2) chosen name a variant of birth name; and (3) chosen name selected for practical reasons.

\section{Emergent theme 1: chosen name selected in order to honor family or heritage}

Namesaking was an important factor in TGNC persons choosing a name that better reflects their authentic self. As one trans-feminine respondent reported, "I kept my middle name as my first name to appease my father (his first name). It is also a feminine name." This choice allowed the respondent to reaffirm ties to their family, while better reflecting their gender identity. A trans-masculine respondent shared, "I chose a name that is common for the boys in my family." These respondents underscore the importance of family in naming. In short, when given the chance to choose a new name, some respondents sought to affirm both their gender identity and their ties to their family.

These affirmations extend beyond choosing family names to involving the family in the renaming process for some respondents. As one trans-masculine respondent shares, "It is what my mother would have named me if I had been born a boy." This new name reflects the name this respondent should have had if their family had known their authentic gender identity. A gender nonconforming respondent took family involvement a step further: "I asked my grandma to pick a new Hebrew name for me." Not only does this decision ground the participants' transition to their authentic self in the family, it links the participant to the family's Hebrew heritage. Namesaking was an important influence on renaming for participants, which allows participants a link to their family through this important process.

\section{Emergent theme 2: chosen name a variant of birth name}

Another choice of many participants was to give themselves a variant of their birth name. As one trans-feminine respondent shared "I have always liked the feminine form of my birth name. So the choice was easy." Beyond liking the gender-opposite variant of a name, other participants reported picking gender neutral forms. As one gender 
non-conforming respondent said, “I wasn't planning on changing my name ... but when I discovered a more gender-neutral variant of my birth name I immediately latched on to it." Keeping a name linked to their original name is a way for respondents to both acknowledge their past self and honor those who named them originally.

\section{Emergent theme 3: chosen name selected for practical reasons}

Aside from names that kept participants linked to their family, other respondents reported that practical issues influenced their choices. Practicality included acknowledgements that keeping the same initials was important. This choice has real-life applications for governmental, employment-related, financial, and other legal documents. Other respondents reported the desire to have the same number of syllables in the new name or that the new name "sounds similar to my other (birth) name" (trans-masculine respondent). By keeping a name that has the same cadence, the respondents are able to more easily transition to responding to being called by the new name.

\section{Discussion}

This exploratory study provides insight into the connection between gender and naming by focusing on adult, TGNC persons. The TGNC community is unique in that, as gender identity is affirmed, a new name may be chosen to reflect and express that gender identity. Indeed, the majority of participants in this study currently used a forename (first name) that was different from their birth name. The adoption of a new name or the renaming of self is in concert with the idea of a "names-body-identity" nexus. Identity is not simply a matter of having a name but having a name connected with a specific body of which gender is an integral part.

Names are not only a way to identify self but also a mechanism to demonstrate connection to family. It has been hypothesized that the practice of namesaking or naming a child after a specific family member may be considered a unique form of parental investment to advertise connection to specific kinfolk (Obasi, 2016). Consistent with Obasi's previous research, respondents who were namesaked were 
more likely to be named after a paternal relative rather than a maternal relative. In addition, several participants indicated a role of family in the adoption of a new name either as the person who selected the new name (e.g. grandmother) or the selection of the new name to be consistent with familial tradition (e.g. a name traditionally used by boys in the family). Indeed, when making the decision to choose a new name, several participants relied on family and family traditions in guiding their selection.

Although this study highlights the importance of family in the renaming process of TGNC persons, one limitation of this study is the lack of racial or ethnic diversity of respondents. The majority of participants in this study identified as White. It would be beneficial, therefore, to build on the initial observations made in this study by exploring gender identity and name selection strategies with a more diverse group of respondents. This future research is warranted especially in light of noted ethnic and racial differences in naming strategies (e.g. Sue \& Telles, 2007).

Of particular interest in this study was the renaming process of participants who identified as gender nonconforming. The increasing realization of gender fluidity demands an understanding of all groups that may fall within the gender spectrum. Results indicated that the majority of gender nonconforming respondents (77.8\%) in this study had been given a typically feminine name at birth. The observations indicated that while $61.1 \%$ of the gender nonconforming participants now use a different forename only $50 \%$ use a gender neutral name; $20 \%$ use traditionally masculine names; and 30\% use traditionally feminine names. These results are intriguing since it was anticipated that gender nonconforming persons were more likely to use gender neutral names. Further research is warranted to investigate renaming amongst gender nonconforming persons.

Empirical research about renaming, name selection, and gender identity is made more salient by the developing practice of raising gender-neutral children referred to as "theybies" (Compton, 2018). Gender neutral parenting includes raising kids using gender neutral pronouns such as "they", "them" and "their" rather than "she", "he", "her", or "him". This form of parenting gained worldwide attention in 2011 when a Canadian family announced they were raising their child Storm without a gender designation. In the subsequent years, there 
has been an increase in the number of parents who have adopted this practice (Compton, 2018). From an onomastic perspective, it would be interesting to see if the increase in theybies is paralleled by an increase in the use of unisex names. The names of publicly-identified gender neutral kids include Kadyn, Searyl Atli, Storm, Zoomer, Zyler (Compton, 2018). It would be informative to determine how parents selected the names of their gender neutral children and the process by which "theybies" identify their place on the gender spectrum and whether or not this is accompanied by a renaming of self associated with gender identity.

Familial influence on the naming of child is well documented (e.g. McAndrew, King \& Honoroff, 2002). Family members are often involved in selecting names for newborns or being a namesake, that is, the person after whom a child is named. Namesaking can be used to advertise and reinforce kinship connections across generations. The importance of family is also evident in the renaming process engaged in by TGNC persons. Indeed, in self-selecting a new name some TGNC persons aimed to affirm both their gender identity and their familial ties.

Disclosure - No potential conflict of interest exists.

\section{Bibliography}

Compton, J. 2018. “'Boy or Girl?’ Parents Raising 'Theybies' Let Kids Decide.” NBCNews.com, NBC Universal News Group, retrieved from www.nbcnews.com/ feature/nbc-out/boy-or-girl-parents-raising-theybies-let-kids-decide-n891836

Haberman, C. 2015. Beyond Caitlyn Jenner Lies a Long Struggle by Transgender People. The New York Times. Retrieved from https://www.nytimes. com/2015/06/15/us/beyond-caitlyn-jenner-lies-a-long-struggle-bytransgender-people.html

McAndrew, F., J. King, J. \& L. Honoroff. 2002. "A Sociobiological Analysis of Namesaking Patterns in 322 American Families.” Journal of Applied Social Psychology 32, no. 4: 851-864.

Obasi, S. 2016. "Naming Patterns in Rural South Central Nebraska." Names: A Journal of Onomastics 64, no. 3: 158-165. http://dx.doi.org/10.1080/00277738 .2016 .1197644

Pilcher, J. 2016. “Names, Bodies and Identities.” Sociology 50, no. 4: 764-779. Rahilly, E. 2015. “Gender-Variant Child: Parents' Negotiations with Childhood Gender Variance." Gender \& Society 29, no. 3: 338-361. 
Reisner, S. L., E.A. Greytak, J.T. Parsons, \& M. Ybarra. 2015. “Gender Minority Social Stress in Adolescence: Disparities in Adolescent Bullying and Substance Use by Gender Identity." Journal of Sex Research 52, no. 3: 243-256. http://doi. org/10.1080/00224499.2014.886321

Slepian, M. L. \& A.D. Galinsky. 2016. “The Voiced Pronunciation of Initial Phonemes Predicts the Gender of Names.” Journal of Personality and Social Psychology 110, no. 4: 509-527. http://dx.doi.org/10. 1037/pspao000041

Sue, C. \& E. Telles. 2007. “Assimilation and Gender in Naming." American Journal of Sociology 112, no. 5: 1383-1415.

\section{Contributors}

Sharon N. Obasi is Assistant Professor of Family Studies at the University of Nebraska at Kearney. Her research interests include parental investment, namesaking and familial relationships, global perspectives on evidence-based family policy, and the scholarship of teaching and learning.

Richard Mocarski is the Assistant Vice Chancellor for Research at the University of Nebraska at Kearney. He is also co-founder of Trans Collaborations, a community-based research group working with the Transgender and Gender NonConforming communities. He is a health communication scholar who researches the impact of socio-cultural factors on health disparities.

Natalie R. Holt is a doctoral student in Clinical Psychology at the University of Nebraska-Lincoln. Her research interests include minority stress processes in LGBTQ individuals and the delivery of evidence-based, culturally-responsive mental health services to TGNC communities.

Debra A. Hope is Aaron Douglas Professor of Psychology at the University of Nebraska-Lincoln and co-founder of Trans Collaborations. She has two primary lines of research: one on mental health impacts of minority stress for individuals who identify as sexual or gender minorities; and the other on assessment and treatment of anxiety, particularly social anxiety.

Nathan Woodruff is co-founder of Trans Collaborations, an academic- community partnership to reduce health disparities for transgender and gender non-conforming people. He is chair of the Local Community Board for Trans Collaborations. He has extensive leadership experience in community advocacy, workshops to improve multicultural competence, and social justice work. 